Article

\title{
What Do Potential Residents Really Want When Hosting a Nuclear Power Plant? An Empirical Study of Economic Incentives in South Korea
}

\author{
Sung-Yoon Huh ${ }^{1}{ }^{\mathbb{D}}$, JongRoul Woo ${ }^{2}$ and Chul-Yong Lee ${ }^{3, *}$ \\ 1 Department of Energy Policy, Seoul National University of Science \& Technology, 232 Gongneung-ro, \\ Nowon-gu, Seoul 01811, Korea; sunghuh@seoultech.ac.kr \\ 2 Institute for Data, Systems, and Society, Massachusetts Institute of Technology, 77 Massachusetts Avenue, \\ Cambridge, MA 02139-4307, USA; jroul86@mit.edu \\ 3 School of Business, Pusan National University, 2, Busandaehak-ro 63beon-gil, Geumjeong-gu, \\ Busan 46241, Korea \\ * Correspondence: cylee7@pusan.ac.kr; Tel.: +82-51-510-2568
}

Received: 8 February 2019; Accepted: 24 March 2019; Published: 28 March 2019

\begin{abstract}
To increase acceptance of new nuclear power plants (NPPs) by local communities, some countries offer those communities economic incentives. This study analyzes potential residents' preferences for economic incentives provided during the construction and operation of NPPs in South Korea. This study uses stated preference data through a discrete choice experiment and the mixed logit model to reflect the heterogeneity of respondents' preferences. The analysis results confirm heterogeneity by various incentive types, and show that respondents consider the distance between the NPP and the residential area as well as reduced electricity bills as crucial attribute of new NPPs. In addition, the result for the marginal willingness to be near to an NPP shows that reduced electricity bills, construction of new public facilities, and increased residents' participation are relatively more effective incentives than job creation or solar panel installation. In particular, increased residents' participation could greatly improve acceptance although it is not a direct form of financial support. The simulation analysis results indicate that acceptance of NPPs rapidly reduces as distance to the plant becomes shorter, although acceptance can change within a 0-30\% range depending on the level of incentives. Several policy implications are suggested for policymakers based on the results.
\end{abstract}

Keywords: nuclear power plant; economic incentive; renewable energy; public acceptance; attitudes

\section{Introduction}

Since climate change has emerged as a global issue, the energy industry and policymakers have been seeking more environmentally friendly and sustainable energy systems. In this context, energy sources in the spotlight are nuclear power and renewable energy. Both renewable energy and nuclear power are currently the main alternatives for reducing carbon emissions in the field of energy [1], and are prime candidates to replace the pre-existing energy system centered on fossil fuels. Thus, establishing their role and relative weight for the future is a crucial element to consider in the electric power system of the country.

Plans regarding their future roles differ according to individual regions, but the general trend is that electricity generation using nuclear power is gradually decreasing around the world while electricity generation using renewable energy is increasing. In 2017, the amount of electricity generated by nuclear power worldwide was $2500 \mathrm{TWh}$, which was $6 \%$ lower than the peak in 2006. Moreover, out of the global electricity production in 2017, the percentage of electricity generated by nuclear power was about $10.3 \%$, showing a continuous decrease from a 1996 peak of $17.5 \%$ [2]. China is rapidly 
increasing the amount of electricity generated by nuclear power, which indicates that most countries are reducing the percentage of the power supplied by nuclear power plants (NPPs). By contrast, at the end of 2017, renewable energy accounted for $26.5 \%$ of global electricity production, showing increasing distribution around the globe [3].

In the meantime, the significance of social acceptance of NPPs is growing day to day in promoting the shift in the power sources. This outcome is because the decision to maintain or replace power sources comes down to social consensus after taking into consideration the benefits and costs of various power sources. Compared to the past, public participation is increasing in the major decision-making in the field of energy, and the level of people's understanding of energy sources has also increased. In this condition, a number of studies that covered consumers' perception and acceptance of nuclear power and renewable energy have been published in recent years [4-7]. In particular, social acceptance of nuclear power is very crucial, because any mishap at an NPP has a deadly and extensive impact on both humans and the environment. Generally, nuclear power has a lower social acceptance than do other power sources $[8,9]$.

Ultimately, smooth implementation of nuclear power policy requires social acceptance, which can be classified into broad acceptance by nationals and local acceptance by the community around the NPP. Of these, low acceptance by local community becomes a serious obstacle in hosting new NPPs. In this case, economic incentives can be provided to local communities that host an NPP to gain their support [10]. Gaining wider acceptance by residents through proper compensation is essential in the process of NPP construction and operation, because safety issues make the support system for the surrounding areas of controversial facilities, such as NPPs, inherently different from the support system around facilities with relatively fewer safety concerns, such as dams and water treatment systems.

Among the countries that provide compensation to the areas surrounding a NPP, South Korea focuses on determining the amount of compensation, based on the appraisal for individual NPPs and discussions with residents. However, the attitude toward an NPP and the preference for economic incentives can vary widely according to individuals, even within the same community. This is why residents' preferences for various economic incentives for hosting an NPP should be accurately analyzed. In addition, the construction of new NPPs and its social acceptance are especially critical policy issues in South Korea. Nuclear power has maintained a very important position in the South Korean electric power supply system for a long time in the situation that the amount of natural resources is insufficient and $95 \%$ of the primary energy is imported. However, since the new government, which was launched in 2017, decided to pursue a nuclear-free policy in the long-term, the South Korean nuclear policy changed rapidly. In addition, public interest in NPPs has greatly increased amid such changes in national energy policy trends, and public debates regarding nuclear power are intensifying, including the launch of an ad-hoc committee to decide whether to stop construction of planned NPPs [11]. Thus, examining how economic incentives for NPPs affect the social acceptance of the local community can give meaningful implications for future nuclear policy of South Korean government.

Another factor to consider is the relationship between renewable energy and nuclear power. As mentioned earlier, these are two main alternatives that can support the next generations following the fossil fuel age. Therefore, providing support in the form of establishing renewable energy facilities can be even more effective environmentally than providing monetary incentives such as reducing electricity bills. Thus, as one of the incentives to the residents for hosting an NPP, the present study postulates a condition that supports the establishment of renewable energy facilities in the concerning area. In doing so, this study examines the effect of this new form of incentive-providing the support for renewable energy facilities- on the residents' acceptance of an NPP.

Under the presumption that a new NPP is to be built in the vicinity of the residential area, this study aims to analyze the potential residents' preferences for incentives and acceptance of an NPP. As a methodology for analysis, this study uses a discrete choice experiment (DCE) and the mixed logit 
model. These analysis tools give researchers general ideas about people's preferences for incentive types for hosting a new NPP and overall acceptance of a hypothetical NPP.

The present study makes the following three contributions. First, this study quantitatively analyzes and compares potential residents' preferences for incentives for hosting a new NPP. A key point is that the analysis reflects the heterogeneity of the respondents' preferences within the process. Based on the result, implications can be drawn for energy policies in countries that are considering introducing new NPPs. Second, this study analyzes the simulation and predicts the acceptance level of an NPP based on distance to power plant and the type of incentives for the surrounding areas of an NPP. Third, this study evaluates the acceptance by residents on condition that the support for solar power facilities will be provided instead of reducing electricity bills. When solar power facilities are provided, the energy system can be more sustainable and environmentally friendly than reducing electricity bills. The evaluation of such a support method is the first attempt in the literature, as far as we know. The research framework used in this study can be applied to other countries' nuclear power policy.

The rest of the paper is structured as follows: Section 2 reviews the literature, particularly studies that mainly focused on economic incentives for acceptance of nuclear power. Section 3 describes a DCE and the mixed logit model as the methods of analysis and explains the survey for collecting data. Section 4 presents the results of the empirical analysis. This section presents the results of analyzing respondents' preferences for incentives offered when hosting a new NPP. Based on this, residents' acceptance of a hypothetical NPP is measured quantitatively. Finally, Section 5 summarizes the study results and provides some concluding remarks.

\section{Literature Review}

Because social acceptance of nuclear power is a crucial issue in the field of energy, studies from various perspectives have been published. Main research topics include analyzing the effect of NPP accidents on the public acceptance of NPP [12,13]; identifying the determinants of nuclear power acceptance [5,14]; suggesting a new method that quantitatively evaluates NPP acceptance [15]; and suggesting a global comparison of public acceptance of nuclear energy [16]. In particular, many studies have measured the public's willingness to pay (WTP) for nuclear power facilities or policy by using non-market good valuation techniques, such as the contingent valuation method $[17,18]$.

In the meantime, not many studies have covered the incentives for residents to host an NPP as the main topic. One reason for this lack of research is that among countries that have NPPs around the world, government-initiated economic incentives for areas around an NPP are not very common, except for South Korea, Japan, and Taiwan [19]. To the best of our knowledge, the following studies are the closest to the present research: [10,20,21]. First, Choi and Lee [20] conducted a conjoint survey and analyzed the result using trade-off analysis to investigate Korean nationals' attitudes and preferences for the types of support given to the areas around NPPs. Specifically, the authors selected 12 support policies of four types (improvement of reactor safety; regulation and monitoring; regional promotion programs; and the subsidy for regional development) and three levels. The data used in their study were collected from 54 mail survey questionnaires targeting secondary school teachers who have been to an NPP. The analysis showed that increasing the safety of the nuclear reactor 100 times and establishing civilian monitoring systems were the two best policies among 12 alternatives to improve the NPP acceptance. This finding confirmed the significance of enhancing the safety of an NPP.

Kato et al. [10] investigated how the Fukushima NPP accident influenced the economic incentives and residents' attitudes toward hosting an NPP in Japan. The authors conducted a questionnaire survey targeting residents within a $10 \mathrm{~km}$ radius of an NPP in 2010 and in 2011, which were before and after the Fukushima accident, and analyzed the data using descriptive statistics and an ordered-probit method. The results of comparing the 2010 and 2011 surveys showed that among various incentives for hosting an NPP, the perceived benefit of reduced electricity bills clearly decreased while the perceived benefit of constructing public facilities did not. As for acceptance of nuclear power after the Fukushima 
accident among the survey areas, residents whose social welfare programs in the community greatly expanded showed less decrease than those whose electricity bills were reduced.

Contu et al. [21] analyzed the consumers' preferences for a fourth-generation NPP in Italy using a DCE. The six attributes used in the DCE are as follows: distance between residence and NPP, the rate of reducing nuclear waste, the reduction of air emissions, the reduction of electricity bills, the construction status of medical facilities, and the status of soil restoration. The analysis results showed much heterogeneity among the respondents in the sample group. Many respondents were opposed to the construction of a new NPP in Italy; some were not interested in receiving any monetary compensation. However, other respondents expected that the long-term goal for a fourth-generation NPP would be achieved, showing a certain level of support for a new nuclear power project.

With regard to the methodology, the present study is similar to Choi and Lee [20] and Contu et al. [21], as they used choice-based stated preference techniques. However, Choi and Lee [20] is somewhat limited in terms of the size (54 respondents) and composition (secondary school teachers) of the data sample. In addition, the attribute and level of incentives were too vague to derive specific implications at this point in time. Meanwhile, Contu et al. [21] included only two incentive-related attributes as part of the acceptance of the fourth-generation NPP project rather than focusing mainly on the economic incentives. Thus, the ultimate goal of Contu et al. [21] differed from that of the present study, which focuses on economic incentives and includes various attributes and levels.

Because the empirical analysis of this study is based on cases in South Korea, it is necessary to examine the Korean studies briefly. The related studies are as follows: identifying the problems of incentive policy for surrounding areas of an NPP [22]; analyzing the satisfaction with and performance of the incentive policy through a questionnaire survey [23]; presenting the current condition of an incentive scheme for surrounding areas of an NPP and suggestions for improvement [24]; and analyzing the effects of financial support to the surrounding area of an NPP on the local economy [19]. These Korean studies have several implications. First, while the size of economic incentives is continually growing and efforts to diversify incentive are continuing, the incentive scheme is inefficiently run and fails to achieve the policy goal of improving NPP acceptance. Moreover, people's distrust in the organizations supervising the incentive policies remains strong. In addition, it is most problematic that the level of residents' satisfaction with the incentive is low. Nevertheless, Korean studies have not progressed beyond the level of qualitative study that presents the conditions and problems of the current incentive scheme. In this light, this study provides unprecedented research with significant implications for policy from a new perspective of social preferences. It does so by quantitatively analyzing the structure of residents' preferences for economic incentive for the surrounding areas of an NPP.

\section{Methods}

\subsection{Survey for Data Collection: Discrete Choice Experiment}

To analyze the structure of residents' preferences and acceptance of the economic incentives for hosting an NPP, it is necessary to identify what alternatives people choose when a new NPP is constructed. Unlike regular consumer goods, the case of an NPP construction does not allow individuals to choose the incentives they want; thus, it is impossible to collect revealed preference data at the level of individuals. To overcome such limitation in the data collection, this study performed a DCE to collect the stated preference data.

A DCE is a method that presents to respondents a few hypothetical goods or service alternatives that consist of main attributes and allows them to select the most preferred alternatives. This method is ideal for collecting people's preference data about new products or services to be launched [25]. This method can elicit the part-worth of the attributes or levels of the goods or services to be analyzed [26]. To design a proper DCE on residents' preferences for economic incentives for an NPP construction, it is essential to identify the main attributes of the new NPP project and to check the respondents' choices over the different levels of attributes and the alternatives. 
The crucial part in designing the questionnaire survey for a DCE is to determine the appropriate attributes and levels of the circumstance for hosting a new NPP. The present study selected six attributes and their levels, as shown in Table 1, by referring to Korean government regulations, actual cases, and previous studies $([20,21,27])$, and by consulting experts in the relevant field. As for other potential attributes that can influence the preferences for a new NPP project, we postulated that all alternatives are the same levels and explained this to the survey respondents in detail.

Table 1. Attributes and levels in the DCE: Construction of a new nuclear power plant and incentives.

\begin{tabular}{cc}
\hline Attributes & Levels \\
\hline \multirow{2}{*}{ 1. Reduced electricity bills } & None \\
& $30 \%$ discount \\
2. Construction of new public facilities & $60 \%$ discount \\
& $90 \%$ discount \\
\hline \multirow{2}{*}{ 3. Job creation } & None \\
& Educational facility \\
L. Residents' participation hospital & Multicultural sport-culture complex \\
\hline \multirow{2}{*}{ 5. Installation of solar panels } & Hiring 1000 people \\
& Hiring 5000 people \\
\hline \multirow{2}{*}{ 6. Distance to the NPP } & Low level \\
& High level \\
\hline & None \\
& Installation (with the installation fee covered 100\%) \\
\hline & $5 \mathrm{~km}$ \\
& $15 \mathrm{~km}$ \\
& $25 \mathrm{~km}$ \\
& $35 \mathrm{~km}$ \\
\hline
\end{tabular}

First, this study included reduced electricity bills as an attribute. In South Korea, the residents of the areas near an NPP receive the benefits of reduced electricity bills as compensation for hosting an NPP. For example, households in the city of Uljin, where Hanul NPP is located, receive an average of $14,510 \mathrm{KRW}$ discount per month on electricity bills [28], which is about $53 \%$ of an average monthly electricity bill (27,335 KRW per month) [29]. This attribute is divided into four discount levels: none, $30 \%, 60 \%$, and $90 \%$.

The second attribute is the construction status of major public facilities, which can affect residents' attitude toward an NPP. The following examples in South Korea show this attribute: multi-purpose sports facilities near Yeonggwang NPP; an indoor sports center and museum for electric power near Hanul NPP; and an autonomous private high school and hospital near Shinhanul NPP. This attribute was divided into four levels encompassing all types of public facilities as follows: none, educational facility, large hospital, and multifunctional sport-culture complex.

The third attribute is job creation. In general, NPPs create large numbers of jobs in the process of construction and operation. In most cases, employees are the residents of the surrounding areas. Some people argue that the management of an NPP does not provide many jobs for residents, because it requires high-level skills and expertise; however, the government or development project managers often take preemptive actions and intentionally prioritize residents for job openings as compensation. The attribute of job creation was divided into two levels: hiring 1000 people and hiring 5000 people.

The fourth attribute is residents' participation. Recently, gaining the active participation of residents regarding the NPP project as well as other energy facility projects has emerged as a crucial factor for successful project implementation [30,31]. The DCE in this study identifies how the degree of residents' participation in the process of hosting a new NPP can affect the local acceptance of the NPP. This attribute was divided into two levels: high and low.

The fifth attribute is the installation of photovoltaic panels on residents' houses. This attribute can demonstrate whether providing renewable energy facilities at the time of hosting a new NPP can elicit 
a positive response from residents. Providing renewable energy facilities can induce the same effect as reduced electricity bills and can educate and promote environmentally friendly power generation. Among various renewable energy facilities, this study selected photovoltaic power generators for households, which are a common sight throughout the country and are widely distributed in South Korea. The government is also developing policies in an effort to encourage wider distribution. The DCE in this study postulated that the residents in surrounding areas of a new NPP are eligible for free installation of photovoltaic power generators. This attribute was divided into two levels: no installation and installation (with the installation fee covered 100\%).

The sixth attribute is the distance between the residential area and a new NPP. The distance between a new NPP and the respondents' place of living affects the attitude and acceptance toward an NPP [32-35]. When the same incentives are provided, people instinctively wish that the NPP were farther away from their residence. This attribute functions as the price attribute of durable goods in a DCE. In other words, the present study analyzed the distance to a new NPP the residents are willing to live from so as to receive certain benefits, instead of using marginal willingness to pay, which is the concept used for normal durable goods in a DCE for the marketing field. The corresponding concept can be expressed as marginal willingness to be near (MWTN). The levels of this attribute range from $5 \mathrm{~km}$ to $35 \mathrm{~km}$.

There are 512 alternative combinations that can be generated by the attributes and levels presented in Table 1. Because it is improbable to present all 512 alternatives to respondents, a total of 16 alternative cards were selected using the fractional factorial design, which ensures the orthogonality between individual attributes. The 16 alternatives cards were randomly mixed and divided into four choice sets, each of which has four alternatives. The sets were presented to each respondent to choose the most preferred alternative.

The survey for the analysis was carried out online for 11 days from 17 June to 27 June, 2016 by a professional survey company (Hankook Research, Seoul, South Korea) targeting 633 male and female Korean adults who were 19 years and older. Because the goal of this study is to identify the preferences of 'potential' residents in a surrounding area of a hypothetical NPP, this study targeted the general public as the respondents of the study, who are not actual residents of a surrounding area of an NPP. To collect the data from a sample similar to actual population composition, this study used purposive quota sampling method for selecting the sample based on gender, age, and region. The characteristics of the respondents are shown in Table 2 above.

Table 2. Descriptive statistics of the respondents.

\begin{tabular}{ccc}
\hline Characteristics & Number of Respondents & Component Ratio (\%) \\
\hline Total & 633 & 100.0 \\
\hline Gender & 320 & \\
Male & 313 & 50.6 \\
Female & & 49.4 \\
\hline Age & 110 & \\
$19-29$ & 122 & 17.4 \\
$30-39$ & 142 & 19.3 \\
$40-49$ & 124 & 22.4 \\
$50-59$ & 135 & 19.6 \\
$>60$ & & 21.3 \\
\hline Education Level & 316 & \\
Under High school & 317 & 49.9 \\
Above undergraduate school & & 50.1 \\
\hline Average Monthly Income $\left(\right.$ KRW $^{\text {a }}$ ) & 104 & \\
$<2$ million & 127 & 16.4 \\
2-3 million & 118 & 20.1 \\
3-4 million & 109 & 18.6 \\
$4-5$ million & 175 & 17.2 \\
$>5$ million & 27.6
\end{tabular}

${ }^{a}$ KRW represents Korean won which is currency of South Korea. 1 USD is equal to 1082 KRW as of 18 May 2018. 


\subsection{Econometric Model: Mixed Logit Model}

The collected survey data through a DCE are analyzed using the discrete choice model based on random utility theory. Because respondents select the alternatives that give them the highest utility among various alternative types of compensation for hosting an NPP, the questionnaire data inherently have a discrete nature. Therefore, the discrete choice model is ideal for achieving the goal of this study. Based on the random utility theory, the utility $U_{n j t}$ of a respondent $n$ by selecting alternative $j$ in choice situation $t$, can be defined as the following Equation (1):

$$
U_{n j t}=V_{n j t}+\varepsilon_{n j t}=\beta^{\prime} x_{j t}+\varepsilon_{n j t}
$$

In this equation, utility $U_{n j t}$ can be divided into deterministic utility $\left(V_{n j t}\right)$ and stochastic utility $\left(\varepsilon_{n j t}\right)$. Deterministic utility $\left(V_{n j t}\right)$ is a clear expression of what most respondents are likely to be influenced by, according to the researcher's judgment; in return, $V_{n j t}$ is influenced by the observable attributes of the alternatives $\left(x_{j t}\right)$. $\beta$ is the preference parameter for the corresponding attribute.

Among many alternatives, each respondent selects the alternative that brings the highest utility. The choice probability that respondent $n$ chooses alternative $j$ in a choice situation $t$ is expressed as follows in Equation (2):

$$
P_{n j t}=\operatorname{Pr}\left(U_{n j t}>U_{n k t} \forall k \neq j\right)=\operatorname{Pr}\left(\varepsilon_{n k t}-\varepsilon_{n j t}<V_{n j t}-V_{n k t} \forall k \neq j\right)
$$

If the random disturbance $\varepsilon_{n j}$ is assumed to follow an independent and identically distributed type-I extreme value distribution, the choice probability that respondent $n$ will choose alternative $j$ in choice situation $t$ is expressed as follows in Equation (3) [36,37]:

$$
P_{n j t}=\frac{\exp \left(V_{n j t}\right)}{\sum_{k=1}^{J} \exp \left(V_{n k t}\right)}, j=1, \cdots, J
$$

Such a discrete choice model is called a multinomial logit model. Generally, it has the advantage of eliciting a simple closed form of the choice probability; however, it cannot reflect consumers' heterogeneity. In addition, it has an unrealistic feature, called independence from irrelevant alternatives (IIA), which indicates that the choice probability ratio of two alternatives is not affected by the change in attributes of irrelevant alternatives. This limitation can be avoided when using the mixed logit model (or random parameter logit model), which incorporates the preference heterogeneity of the respondents and relaxes the IIA property.

The mixed logit model reflects the heterogeneity of respondents' preferences by assuming that the preference parameter vector $\beta$ follows a certain distribution. The probabilities of the mixed logit model can be expressed as integrals of multinomial logit probabilities over the assumed distribution function of $\beta, f(\beta)$. Generally, the vector of preference parameters is assumed a normal distribution with mean $(b)$ and covariance $(W)$. Then, the choice probability of the mixed logit model can be expressed as Equation (4):

$$
P_{n j t}=\int \frac{\exp \left(V_{n j t}\right)}{\sum_{k=1}^{J} \exp \left(V_{n k t}\right)} f(\beta \mid b, W) d \beta
$$

As for the mixed logit model, the form of the likelihood function is too complicated to apply the classical maximum likelihood estimation (MLE) method. Thus, to solve this problem, we used a Bayesian inference method, the hierarchical Bayesian method, for the estimation [38]. Compared to the MLE method, the Bayesian method has the advantage of solving the problem of global maximization and the problem of initial value [38-40]. 
The estimated preference parameters can be used to calculate the MWTN, which is the willingness to reside near a new NPP to gain a certain incentive. In other words, the MWTN refers to either a short or long distance to an NPP that a respondent is willing to be located so as to maintain his or her utility when the quantity or quality of attributes changes by one unit:

$$
\operatorname{MWTN}_{a}=-\frac{\partial U / \partial x_{a}}{\partial U / \partial x_{\text {distance }}}=-\frac{\hat{\beta}_{a}}{\hat{\beta}_{\text {distance }}}
$$

In Equation (5), $\hat{\beta}_{a}$ and $x_{a}$ indicate the mean estimated parameters and the incentive attributes, respectively, excluding the attribute of distance to the power plant. $\hat{\beta}_{\text {distance }}$ and $x_{\text {distance }}$ are the estimated parameter and the distance attribute, respectively.

The relative importance (RI) of each attribute represents how much each attribute contributes to the choice of a respondent. The value can be calculated by using the part-worth of each attribute, as follows:

$$
R I_{a}=\frac{\text { part }- \text { worth }_{a}}{\sum_{a} \text { part }- \text { worth }_{a}} \times 100
$$

In Equation (6), the part-worth of attribute $a$ can be obtained by multiplying the estimated coefficient value of attribute $a$ by the interval of the attribute's level (maximum level minus minimum level).

\section{Results and Discussion}

\subsection{Preliminary Questionnaire: Respondents' Perceptions of Nuclear Power}

Prior to the econometric analysis, it is necessary to examine the overall perceptions of respondents about nuclear energy at the time of participating in the survey. Such a task prior to a DCE survey not only can call the respondents' attention to the issue of NPP but also can provide a meaningful finding in itself.

First, this study examined the respondents' overall perceptions and level of knowledge about nuclear power. To assess the perceived level of knowledge, the respondents were given questions using a 5-point Likert scale about how well they know the advantages and disadvantages of nuclear power. The survey data showed the following result: among 633 respondents, $4.6 \%$ responded "not at all aware"; $28.1 \%$ responded "slightly aware"; $45.0 \%$ responded "somewhat aware"; $19.9 \%$ responded "moderately aware"; and $2.4 \%$ responded "extremely aware." The distribution showed a pattern similar to a normal distribution. This result implies that the survey sample did not have sample selection bias regarding the question about the level of knowledge of nuclear power. To examine the respondents' perceived danger of nuclear power, the respondents were asked the following question: "How do you perceive the danger or the safety of the nuclear power?" In response, $8.8 \%$ selected "very dangerous"; $42.2 \%$ selected "somewhat dangerous"; $31.6 \%$ selected "neutral"; $16.6 \%$ selected "somewhat safe"; and $0.8 \%$ selected "very safe." While more than half of the respondents perceived electricity generation by nuclear power as dangerous, the proportion of respondents who considered it neutral or rather safe (49\%) was higher than expected. This result shows that perceived danger of NPPs varies depending on individual respondents. Because the perceived danger and the social acceptance of nuclear power are closely related [41,42], the presence of heterogeneity in the concerning item implies that there will be heterogeneity in the acceptance of NPPs in South Korea. To identify the status of respondents' awareness about the NPP accident in Fukushima, which influenced the public's attitude toward NPPs throughout the world, the respondents were asked the following question: "Have you heard of the Fukushima accident that occurred in Japan in 2011?" According to the survey result, $98.1 \%$ of the respondents had heard and $1.9 \%$ of the respondents had not. This result showed that almost all respondents remembered the accident at the time of reporting, which was 5 years after the accident. To gauge the role of nuclear power in providing electric power in South Korea, the respondents were asked the following question: "How necessary do you think it is to 
increase electricity generation by nuclear power in South Korea?" In response, 5.7\% answered "not at all necessary"; $19.7 \%$ answered "Mostly unnecessary"; $36.5 \%$ answered "neutral"; $34.1 \%$ answered "necessary"; and 3.9\% answered "very necessary." The percentage of respondents who believed that it is necessary to increase NPPs (38\%) was higher than those who disagreed $(25.4 \%)$, which indicates that some respondents acknowledged the need for NPPs in supplying electric power in Korea.

To examine the respondents' views on the construction of a new NPP near their residential areas, the respondents were asked the following question: "Are you for or against hosting a new NPP near your residence?" This question is the most relevant to the main topic of this study. The survey result showed that $24.5 \%$ responded "strongly oppose"; $38.7 \%$ responded "Somewhat oppose"; $26.2 \%$ responded "neutral"; 9.3\% responded "somewhat favor"; and 1.3\% responded "strongly favor." As expected, the percentage of opposing respondents (63.2\%) was predominantly higher than the percentage of supporting residents $(10.6 \%)$. This finding indicates that the phenomenon of "not in my backyard" (NIMBY) emerged, as the respondents were opposed to hosting a new NPP near their residence, although they had given unexpectedly favorable responses toward NPPs in the previous question about the perceived danger of NPPs and the question about the necessity of increasing the number of NPPs. Such a phenomenon showing consensus on the necessity for NPPs yet changing this attitude when it comes to the issue of their own residence is often observed in other surveys previously undertaken in South Korea [43]. In addition, this NIMBY phenomenon is found in other studies about nuclear facilities or radioactive waste [44-48]. Based on the finding from the basic questionnaire survey, it appears that Korean people's perceptions of nuclear energy and the construction of NPPs have not changed much despite the efforts of the central government to improve the social acceptance of nuclear power.

\subsection{Model Estimation: Preference Structure for Construction of a New Nuclear Power Plant}

With regard to the respondents' preferences in the utility function in Equation (7), the mixed logit model with Bayesian method was used for the estimation. By using Markov Chain Monte Carlo (MCMC), the posterior distribution of the coefficient was extracted through several sequential steps. The MCMC chain used in the estimation kept the values from the 10th round of extraction after repeating 10,000 times, and calculated the estimated value by using the last 500 values out of the remaining 1000 values:

$$
\begin{aligned}
U_{n j}=\beta_{1} X_{\text {bills }}+ & \beta_{2} D_{\text {education }}+\beta_{3} D_{\text {hospital }}+\beta_{4} D_{\text {Mfacility }}+\beta_{5} X_{\text {job }} \\
& +\beta_{6} D_{\text {part }}+\beta_{7} D_{\text {pv }}+\beta_{8} X_{\text {distance }}+\varepsilon_{n j}
\end{aligned}
$$

In Equation (7), variable $X_{\text {bills }}$ is the percentage of reduced electricity bills and variable $X_{j o b}$ is the number of created jobs. $D_{\text {education }}, D_{\text {hospital }}$, and $D_{\text {Mfacility }}$ are dummy variables and subgroups of major public facility construction. Either 1 or 0 is assigned to each dummy variable, depending on whether any major public facilities (e.g., education facilities, large medical facilities, and multifunctional sports and culture facilities) are newly constructed as an incentive for hosting an NPP: 1 for new construction and 0 for no construction. $D_{p a r t}$, and $D_{p v}$ are dummy variables that represent residents' participation and solar panel installation, respectively. The dummy variable takes 1 when the participation level is high or when solar panel installation fees are paid. Finally, $X_{\text {distance }}$ means the distance between the power plant and the respondent's residence.

The mixed logit model generally assumes that the preference coefficient follows the pattern of normal distribution. Accordingly, the present study also assumed that preference coefficient vector $\beta$ follows the pattern of multivariate normal distribution with mean $b$ and covariance $W$.

The estimated results based on the model are presented in Table 3. Specifically, Table 3 shows the mean $(b)$ of preference coefficient $(\beta)$ from the Bayesian estimation, variance $(W)$, the average MWTN, and the relative importance calculated based on this estimation. 
Table 3. Estimation based on the mixed logit model: Social preferences for incentives for hosting a new nuclear power plant.

\begin{tabular}{|c|c|c|c|c|}
\hline Attributes & Mean (b) & Variance (W) & MWTN & RI (\%) \\
\hline $\begin{array}{l}\text { Reduced electricity bills } \\
\text { (Unit: \%) }\end{array}$ & $\begin{array}{l}2.9549 * \\
(0.2426)\end{array}$ & $\begin{array}{l}6.8174 * \\
(1.0580)\end{array}$ & $\begin{array}{c}-0.27 \\
(\mathrm{~km} / \text { discount \%p) }\end{array}$ & 21.22 \\
\hline $\begin{array}{l}\text { Construction of new public } \\
\text { facilities: Educational facility } \\
\text { (Base: None) }\end{array}$ & $\begin{array}{l}0.9670 * \\
(0.1061)\end{array}$ & $\begin{array}{l}0.8411 * \\
(0.1993)\end{array}$ & $\begin{array}{c}-8.67 \\
(\mathrm{~km} / \text { installation })\end{array}$ & 7.71 \\
\hline $\begin{array}{l}\text { Construction of new public } \\
\text { facilities: Large hospital } \\
\text { (Base: None) }\end{array}$ & $\begin{array}{l}1.2817 * \\
(0.1492)\end{array}$ & $\begin{array}{l}4.2361 * \\
(1.0884)\end{array}$ & $\begin{array}{c}-11.50 \\
(\mathrm{~km} / \text { installation })\end{array}$ & 10.22 \\
\hline $\begin{array}{l}\text { Construction of new public } \\
\text { facilities: Sport-culture } \\
\text { complex (Base: None) }\end{array}$ & $\begin{array}{l}1.6127 * \\
(0.1240)\end{array}$ & $\begin{array}{l}1.6689 * \\
(0.3976)\end{array}$ & $\begin{array}{c}-14.51 \\
(\mathrm{~km} / \text { installation })\end{array}$ & 12.90 \\
\hline $\begin{array}{l}\text { Job creation } \\
\text { (Unit: } 1000 \text { people) }\end{array}$ & $\begin{array}{l}0.1750 * \\
(0.0307)\end{array}$ & $\begin{array}{l}0.0912 * \\
(0.0186)\end{array}$ & $\begin{array}{c}-1.57(\mathrm{~km} / 1000 \\
\text { people })\end{array}$ & 5.59 \\
\hline $\begin{array}{l}\text { Residents' participation } \\
\text { (Base: low level) }\end{array}$ & $\begin{array}{l}1.2427 * \\
(0.1472)\end{array}$ & $\begin{array}{l}1.5802 * \\
(0.3144)\end{array}$ & $\begin{array}{c}-11.16(\mathrm{~km} / \mathrm{high} \\
\text { level })\end{array}$ & 9.92 \\
\hline $\begin{array}{l}\text { Installation of solar panels } \\
\text { (Base: None) }\end{array}$ & $\begin{array}{l}0.7191 * \\
(0.1384)\end{array}$ & $\begin{array}{l}2.7658 * \\
(0.5629)\end{array}$ & $\begin{array}{c}-6.48 \\
(\mathrm{~km} / \text { installation })\end{array}$ & 5.76 \\
\hline $\begin{array}{l}\text { Distance to the power plant } \\
\text { (Unit: } 10 \mathrm{~km})\end{array}$ & $\begin{array}{l}1.1125^{*} \\
(0.0831)\end{array}$ & $\begin{array}{l}1.0446 * \\
(0.1670)\end{array}$ & - & 26.68 \\
\hline
\end{tabular}

* Significant at $99 \%$ reliability level; values in parentheses indicate the standard deviation of the a posteriori distribution.

The analysis showed that the mean and variance of all attributes were significant at the $99 \%$ reliability level. This finding indicates that all attributes in the empirical analysis model exert a significant effect on preferences regarding a new NPP and that people have significantly different preferences for attributes in terms of statistics. In particular, as for reduced electricity bills, construction of large medical facilities among other public facilities, and solar panel installation support, the variance values are greater than are those for other variables. This finding indicates that people have a relatively more heterogeneous structure of preferences for these three attributes. In other words, there is a lower level of social consensus on the incentives for hosting a new NNP for the three variables than for the other attributes, which means the three attributes are the incentives that are likely to be more controversial among residents in the future.

The signs of the estimated coefficients are found (in the second row of Table 3 ) to be positive (+) in all eight estimated coefficients. This result indicates that the level of preference for NNP construction improves under the following circumstances: when the percentage of reduced electricity bills increases; when major public facilities, such as education facilities, large medical facilities, and multifunctional sports and culture facilities, are constructed; when more jobs are created; when residents' participation increases; when solar panel installation is subsidized; and when the distance from residence to power plant is far. This finding matches the intuitive perception and the common direction that project authorities also pursue as long as the technical and geographical conditions (easy access to water and solid bedrock structure) and budgets allow them. In other words, the result of analyzing the relevant attributes revalidates the foundational principle - that meeting the residents' preferences involves locating a new NNP in the area with the lowest population density and striving to provide various incentives to the surrounding areas of a new NNP.

While the estimation of the coefficient in Table 3 is ideal for discovering the direction of respondents' preferences regarding each attribute, it is not ideal for comparing the level of respondents' preferences regarding individual attributes, because each attribute uses a different unit for measuring the levels. Thus, it is necessary to calculate the average MWTN of all respondents for each attribute 
and to compare them (the fourth row in Table 3). The respondents indicated their willingness to reside $0.27 \mathrm{~km}$ closer to an NNP as the electricity bill reduction rate increased by $1 \%$; they were willing to reside $8.67 \mathrm{~km}, 11.50 \mathrm{~km}$, and $14.51 \mathrm{~km}$ closer to an NPP as education facilities, large medical facilities, and a multifunctional sports and culture complex are constructed, respectively. In particular, with regard to reduced electricity bills, it is possible to construct an NPP up to $27 \mathrm{~km}$ away from the residence, because the bills can be $100 \%$ exempt in theory. In addition, people were willing to reside $1.57 \mathrm{~km}$ and $11.16 \mathrm{~km}$ from a power plant when new jobs are created for 1000 people by a new NPP and when residents fully participate in the process of hosting an NPP. Finally, as for photovoltaic power generators for households as the incentive for hosting an NPP, the residents were willing to reside $6.48 \mathrm{~km}$ from an NPP. From the perspective of MWTN, providing support for solar panel installation was found to be less effective than other incentives in improving the acceptance of an NPP.

Finally, the result analyzing relative importance (bottom row of Table 3) showed that people considered the distance between residence and NPP as the most crucial factor in selecting the condition of a new NPP (RI 26.68\%). The second most crucial factor was the benefit of reduced electricity bills $(21.22 \%)$. According to previous studies on preferences for electricity power services, the attribute of electricity bills was identified as the most significant factor that determined preferences regarding an electric power plant, which could significantly control the level of acceptance based on the amount of energy bills [49-51]. However, the findings from the present study showed that the most significant factor in relation to an NPP is the distance between residence and the NPP, which was more significant than the attribute of reduced energy bills. This could be due to the public impression of NPPs as unpleasant facilities and apprehension about safety. Besides distance and electricity bills, this study found that people considered the attribute of new public facilities $(12.90 \%$ for a multifunctional sports and culture complex, $10.22 \%$ for a large medical facility, and $7.71 \%$ for an education facility) and residents' participation $(9.92 \%)$ as fairly important. This can be interpreted as follows: people consider public facilities as important owing to their relevance to the actual daily life of residents and the visual effect is immediate from the start of construction. As for residents' participation, it appears to reflect the relative importance from the distrust in the previous NPP policies that were decided and implemented in a top-down manner. This gives an implication for the future-that a systematic channel should be established so that residents can directly participate in a transparent decision-making process, ultimately improving the acceptance of an NPP. In the meantime, job creation (5.59\%) and solar panel installation (5.76\%) showed low levels of relative importance around $5 \%$. This finding indicates that people did not consider these attributes important in the process of hosting a new NPP. The vitalization of local economy through job creation takes a long time to trickle down to respondents and they may think that the available jobs are for outsiders rather than residents. As for the photovoltaic power generators for households, it appears that the respondents have not fully comprehended the benefit (e.g., reduced electricity bills from solar panel installation) compared to other attributes, although solar panels have been distributed around the country rapidly in recent years.

\subsection{Choice Probability Simulation: Predicting Residents' Acceptance of a New Nuclear Power Plant}

One of the advantages of the discrete choice model is that it can calculate residents' choice probability of hypothetical alternatives based on the estimated coefficient and the levels of attributes (scenarios). The choice probability is viewed as the residents' acceptance of the condition about individual NPP construction. Therefore, in this subsection, the same calculation method as choice probability is used to predict the residents' acceptance of the construction of a hypothetical NPP. In particular, a simulation was used to examine the actual effect of various incentives provided to a surrounding area of an NPP. To this end, two scenarios were designed and the choice probability of each scenario was calculated. Specifically, a simulation was carried out to discover which of the following two scenarios the respondents would choose: (i) a standard scenario in which the residents do not receive any benefits and an NPP is built far away from their residence (50 km); and (ii) an alternative scenario in which the residents receive benefits and an NPP is built near their residence 
$(10-1 \mathrm{~km})$. Prior to the simulation, this study took into consideration the circumstances regarding the radius; although the areas within a 5-km radius of a power plant are legally eligible for incentives in South Korea, there are demands to increase the radius to $10 \mathrm{~km}$. This study also took into consideration that the emergency planning zone (EPZ) in the case of a nuclear accident is about 10 miles in the United States [52,53]. This study calculated the change in the choice probability in both scenarios while maintaining the standard scenario, and adjusting the alternative scenario in terms of distance and incentives.

The levels of attributes in the selected scenarios are outlined in Table 4. Again, the standard scenario is "building an NPP far from the residential area without providing any incentives" while the alternative scenario is "building an NPP near the residential area while providing incentives." Among the five alternative scenarios, alternative scenario-Reference (Asc-Ref) can be considered a type of reference incentive with the lowest levels of incentives. Compared to Asc-Ref, the remaining scenarios, including Asc-Fare, Asc-Infra, Asc-Part, and Asc-Solar, are enhanced scenarios that add reduced electricity bills, construction of public facilities, residents' participation, and providing support for solar panel installation; they demonstrate the effect of individual incentives.

Table 4. Design of standard and alternative scenarios.

\begin{tabular}{|c|c|c|c|c|c|c|}
\hline Attribute & Base SC & ASc-Ref & ASc-Fare & ASc-Infra & ASc-Part & ASc-Solar \\
\hline $\begin{array}{l}\text { 1. Reduced } \\
\text { electricity bills }\end{array}$ & None & $50 \%$ & $100 \%$ & $50 \%$ & $50 \%$ & $50 \%$ \\
\hline $\begin{array}{l}\text { 2. Construction of } \\
\text { new public facilities }\end{array}$ & None & None & None & $\begin{array}{l}\text { Sport-culture } \\
\text { complex }\end{array}$ & None & None \\
\hline 3. Job creation & None & 2000 people & 2000 people & 2000 people & 2000 people & 2000 people \\
\hline $\begin{array}{l}\text { 4. Residents' } \\
\text { participation }\end{array}$ & Low & Low & Low & Low & High & Low \\
\hline $\begin{array}{l}\text { 5. Installation of } \\
\text { solar panels }\end{array}$ & None & None & None & None & None & Installation \\
\hline $\begin{array}{l}\text { 6. Distance to the } \\
\text { power plant }\end{array}$ & $50 \mathrm{~km}$ & $10-1 \mathrm{~km}$ & $10-1 \mathrm{~km}$ & $10-1 \mathrm{~km}$ & $10-1 \mathrm{~km}$ & $10-1 \mathrm{~km}$ \\
\hline
\end{tabular}

Note: The bold part indicates the improved level of incentive compared to ASc-Ref.

Figure 1 shows the alternative scenarios' choice probability (acceptance) based on the hypothetical levels of attributes in the scenarios. First, the effect of each incentive can be compared by analyzing the individual scenarios. As for Asc-Ref, the rate of acceptance was very low, around 2.58-6.74\%. This can be interpreted as follows: a new NPP that provides a low level of incentives rarely gains acceptance from residents. Put differently, implementing incentive projects for residents in the surrounding areas is absolutely necessary for acceptance of an NPP.

As for Asc-Infra, it was found that the construction of multifunctional facilities among other incentives is the most effective way to improve residents' acceptance of a new NPP. When a new facility is to be constructed around the power plant, the percentage of residents who chose to reside within the $1-10 \mathrm{~km}$ radius of a new NPP increased from $11.77 \%$ up to $26.65 \%$ (in the standard scenario, the proportion decreased from $88.23 \%$ to $73.35 \%$ ). In particular, when the said level of incentive is provided to the residents within a 10-km radius of a new NPP, it is predicted that the residents' acceptance rate would surpass $25 \%$ exceptionally among other alternative scenarios. This result is consistent with that of [10] that the perceived benefits did not diminish even after the NPP accident.

Next to the construction of multifunctional facilities, the result for Asc-fare showed that reducing electricity bills is the second most effective way to improve residents' acceptance of a new NPP. When the rate of reduced electricity bills increased from 50\% in Asc-ref to 100\% in Asc-fare, the percentage of respondents who accepted the construction of a new NPP within a $5-\mathrm{km}$ radius in the standard scenario increased considerably from $3.98 \%$ to $15.34 \%$. Next to reduced electricity bills, it was found that raising the level of residents' participation and providing support for solar panel installation were effective for improving the level of acceptance. 


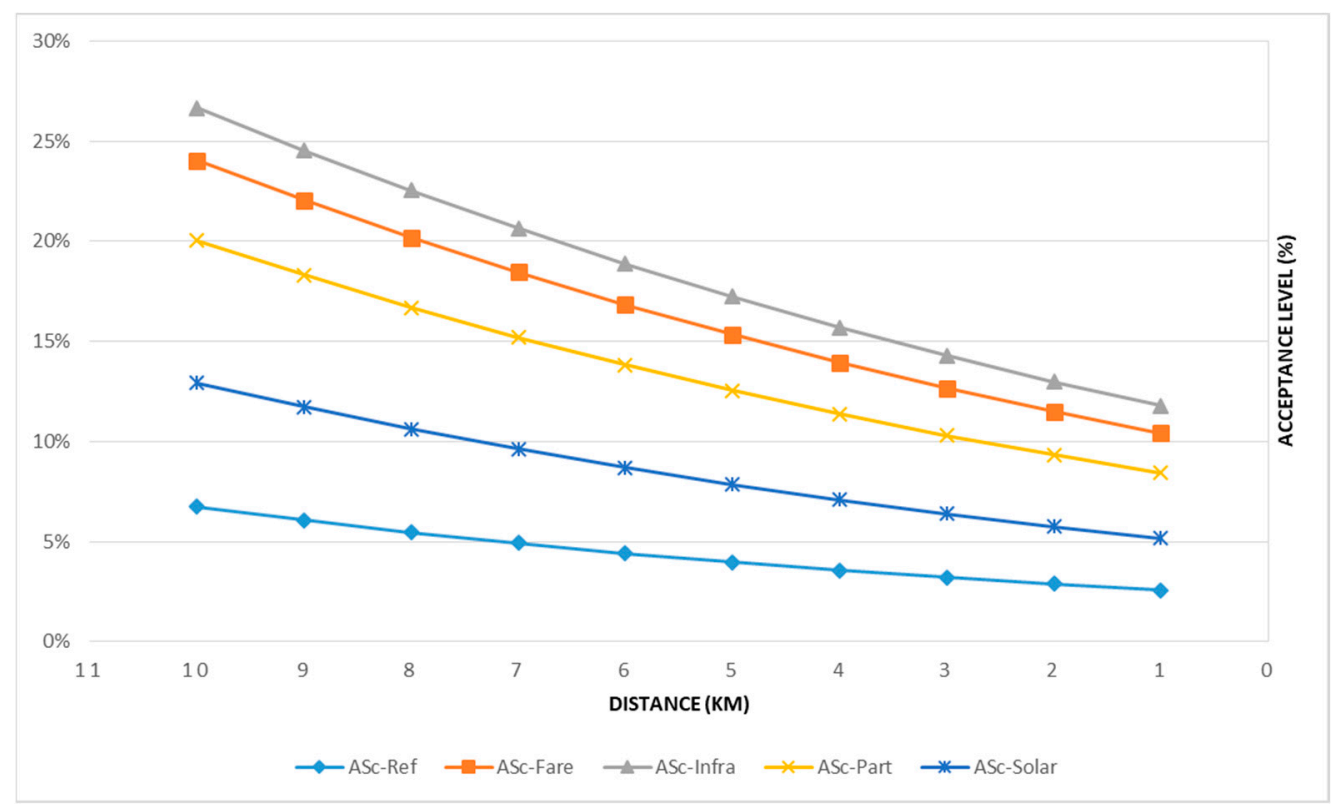

Figure 1. Prediction of NPP acceptance based on the incentives for surrounding areas.

Above all, it is clear that the acceptance rate rapidly decreases in all scenarios regardless of type and level of incentives as the distance to an NPP becomes shorter. As confirmed in Section 4.2 about the relative importance of the estimated result, the distance between the residence and an NPP exerts the greatest effect on the utility of residents regarding the construction of a new NPP. In other words, from the perspective of maximizing the residents' utility, it is more significant to select the location of a new NPP far from densely populated areas prior to planning incentives.

Finally, the cost-effectiveness of incentives for surrounding areas of an NPP can be compared between alternative scenarios. The goal of this task is to select the incentives that can boost residents' acceptance with limited financial resources. Among the five incentives used in this study (the attribute of distance is excluded because it is not an incentive), the estimated financial resources fluctuate greatly depending on the qualitative nature of constructing public facilities, creating jobs, and improving the level of residents' participation. By contrast, reducing electricity bills and providing support for household solar panel installation are comparatively easy to compare, because there is a guideline for support, which allows researchers to estimate the average amount of the subsidy for one household. For this reason, this study used these two incentives (reducing electricity bills and providing support for household solar panel installation) to calculate the subsidy for individual households.

To this end, it is necessary to discover the levels of residential electricity bills and photovoltaic power generators for households in South Korea. First, the average electricity bill for a household is about 27,500 KRW per month [29]. Therefore, when calculating the current value (with a 3\% interest rate) based on the presumption that the government pays 27,500 KRW per month for the rest of the resident's life, the value is about 11 million KRW. This study used the following equation to calculate the current value of a permanent bond, which pays the fixed interest rate for life time:

$$
\text { current value }=\text { annual expenditure } / \text { annual interest rate }
$$

In the meantime, according to [54], $3 \mathrm{~kW}$ photovoltaic power generators are generally installed in households in Korea, and an installation costs around 5.5 million KRW on average (about 1.83 million $\mathrm{KRW}$ per $\mathrm{kW}$ ). In the end, the estimated amount of the subsidy provided to each household in the alternative scenarios based on these two attributes is as follows: the scenarios of Asc-Ref and Asc-Part provide about 5.5 million KRW per household while the scenarios of Asc-Fare and Asc-Solar provide 
about 11 million KRW. Asc-Infra is excluded from the comparative analysis because the amount of the subsidy differs greatly depending on the size and quality of the facility.

First, a comparison of the pairs with the same amount of subsidy per household (Asc-Ref and Asc-Part; Asc-Fare and Asc-Solar) showed that the same amount of the subsidy does not necessarily lead to the same level of acceptance. Particularly, it was found that the direct form of incentive by reducing electricity bills was more cost-effective than providing the subsidy for solar panel installation. In most distances, the level of residents' acceptance of Asc-fare was double that of Asc-solar. Accordingly, it can be interpreted that people prefer more definite monetary benefits than uncertain benefits and inconvenience from installing solar panels. This result could be because people do not put much value on the positive effects that can be gained from solar panel installation, such as greenhouse gas emission reduction. Other effects cannot be expected from the incentive of reduced electricity bills, except for monetary benefits, but it could generate negative consequences, such as encouraging beneficiaries to waste electric energy. Therefore, the Korean government needs to actively promote among people various external benefits of solar panel installation, including greenhouse gas reduction, enhancing safe energy, and developing related industries. Moreover, considering that the cost of solar panel installation remains high and is not cost-effective, it appears that this cost must continue to drop in order to improve the level of acceptance of solar panel installation. This is an area that should be addressed by the solar panel industry.

Meanwhile, when comparing ASc-Solar with ASc-Part, it is clear that a huge economic incentive does not necessarily guarantee a high level of acceptance. In particular, although increasing residents' participation is not a direct form of economic incentive, it was found to improve residents' acceptance considerably. This result is consistent with the findings from previous research on energy $[31,55,56]$. In this light, the Korean government should take action to seek measures that can improve the level of residents' participation in the process of selecting a site.

\section{Conclusions}

It is imperative to gain a high level of residents' acceptance for future construction of a new NPP and further promotion of the smooth implementation of nuclear power policies; thus, it is crucial to pay attention to the provision of economic incentives in NPP host areas as a future measure. The present study analyzed the structure of potential residents' preferences for incentives for hosting a new NPP. Based on the analysis, this study quantitatively predicted the level of acceptance of incentives for a new hypothetical NPP. As analysis methodology, this study used a DCE and the mixed logit model.

The result of the basic questionnaire survey showed the presence of the NIMBY phenomenon with residents opposing the construction of a new NPP near their residence while acknowledging the necessity of NPPs in supplying electric power in South Korea. The estimation results based on the mixed logit model showed the presence of heterogeneity in respondents' preferences for various incentives. In particular, the result calculating the MWTN showed that, compared to the incentive of constructing public facilities, such as an education facility, a large medical facility, or a sports and culture complex, and to the incentive of involving residents in the process of implementing the project, the incentive of installing solar panels was less effective in improving the level of acceptance. In addition, from the perspective of relative importance, people considered the distance between their residence and the NPP as well as the benefit of reduced electricity bills as important in hosting the new NPP. Analysis of the simulation result showed that the level of NPP acceptance could change variably within a $0-30 \%$ range depending on the level of economic incentives. In addition, this study discovered that regardless of the type and level of incentives, the acceptance level rapidly decreases as the distance to an NPP becomes shorter. Furthermore, the size of the economic incentive is not proportionate to the acceptance level.

Finally, the present study has the following limitations. First, the DCE in this study limited the number of attributes for the respondents to consider at the time of hosting an NPP to six attributes. We did so because respondents feel overwhelmed when the number of attributes exceeds six items in 
a DCE [57] and the main goal of this study was to analyze the structure of residents' preferences for incentives for hosting an NPP. However, the six attributes used in this study do not reflect all factors that respondents consider in the process of hosting an NPP; therefore, a follow-up study needs to take into account other attributes that may affect the acceptance of an NPP. Second, the data used in this study have limitations in two ways. The first is the limitation inherent in the stated preference data. The biggest weakness of the stated preference method is that it uses hypothetical situations; the preferences stated by respondents can completely change in real-life situations. The other limitation is a regional restriction. The data used in this study were collected in South Korea and discretion is necessary in generally applying the study findings to other places or countries. Finally, with the goal of investigating the preferences of residents in areas hosting a potential NPP, the present study surveyed the general public instead of actual residents living near an NPP. As a future research, it is necessary for researchers to conduct a survey among actual residents in the host area of an NPP and to compare the results with those of the present study.

Author Contributions: S.Y.H. designed the study, outlined the methodology, and developed the model. J.R.W. estimated the model. C.Y.L. reviewed the related literature, set up scenarios for simulation, and interpreted the results. All authors provided substantial writing contributions and significant comments on numerous drafts.

Acknowledgments: This work was supported by Korea Energy Economics Institute (KEEI) grant funded by the Korea Hydro \& Nuclear Power Co., Ltd. Sung-Yoon Huh was also supported by the Korea Institute of Energy Technology Evaluation and Planning (KETEP) and the Ministry of Trade, Industry \& Energy (MOTIE) of the Republic of Korea (No. 20184030202230).

Conflicts of Interest: The authors declare no conflict of interest.

\section{References}

1. Verbruggen, A. Renewable and nuclear power: A common future? Energy Policy 2008, 36, 4036-4047. [CrossRef]

2. Schneider, M.; Froggatt, A. The World Nuclear Industry Status Report 2018; A Mycle Schneider Consulting Project: Paris, France, 2018.

3. REN21. Renewables 2018 Global Status Report; REN21 Secretariat: Paris, France, 2018.

4. Wustenhagen, R.; Wolsink, M.; Burer, M.J. Social acceptance of renewable energy innovation: An introduction to the concept. Energy Policy 2007, 35, 2683-2691. [CrossRef]

5. Visschers, V.H.M.; Keller, C.; Siegrist, M. Climate change benefits and energy supply benefits as determinants of acceptance of nuclear power stations: Investigating an explanatory model. Energy Policy 2011, 39, 3621-3629. [CrossRef]

6. Sutterlin, B.; Siegrist, M. Public acceptance of renewable energy technologies from an abstract versus concrete perspective and the positive imagery of solar power. Energy Policy 2017, 106, 356-366. [CrossRef]

7. Wu, Y. Public acceptance of constructing coastal/inland nuclear power plants in post-Fukushima China. Energy Policy 2017, 101, 484-491. [CrossRef]

8. Renn, O. Public acceptance of energy technologies. In European Strategy for Energy Research and Technological Development, Proceedings of the Seminar Proceedings, Venezia, Italy, 18-20 November 1993; Office for Official Publications of the European Community: Luxemburg, 1994; pp. 77-93. ISBN 92-825-9199-9.

9. Devine-Wright, P. A cross-national, comparative analysis of public understanding of, and attitudes towards nuclear, renewable and fossil-fuel energy sources. In Proceedings of the 3rd Conference of the EPUK (Environmental Psychology in the UK) Network: Crossing Boundaries-The Value of Interdisciplinary Research, Aberdeen, UK, 2003; pp. 160-173.

10. Kato, T.; Takahara, S.; Nishikawa, M.; Homma, T. A case study of economic incentives and local citizens' attitudes toward hosting a nuclear power plant in Japan: Impacts of the Fukushima accident. Energy Policy 2013, 59, 808-818. [CrossRef]

11. Woo, J.; Lim, S.; Lee, Y.G.; Huh, S.Y. Financial feasibility and social acceptance for reducing nuclear power plants: A contingent valuation study. Sustainability 2018, 10, 3833. [CrossRef]

12. Siegrist, M.; Visschers, V.H.M. Acceptance of nuclear power: The Fukushima effect. Energy Policy 2013, 59, 112-119. [CrossRef] 
13. Visschers, V.H.M.; Siegrist, M. How a nuclear power plant accident influences acceptance of nuclear power: Results of a longitudinal study before and after the Fukushima disaster. Risk Anal. 2013, 33, 333-347. [CrossRef]

14. Keller, C.; Visschers, V.; Siegrist, M. Affective imagery and acceptance of replacing nuclear power plants. Risk Anal. 2012, 32, 464-477. [CrossRef]

15. Liu, C.; Zhang, Z.; Kidd, S. Establishing an objective system for the assessment of public acceptance of nuclear power in China. Nucl. Eng. Des. 2008, 238, 2834-2838. [CrossRef]

16. Kim, Y.; Kim, W.; Kim, M. An international comparative analysis of public acceptance of nuclear energy. Energy Policy 2014, 66, 475-483. [CrossRef]

17. Jun, E.; Kim, W.J.; Jeong, Y.H.; Chang, S.H. Measuring the social value of nuclear energy using contingent valuation methodology. Energy Policy 2010, 38, 1470-1476. [CrossRef]

18. Sun, C.; Zhu, X. Evaluating the public perceptions of nuclear power in China: Evidence from a contingent valuation survey. Energy Policy 2014, 69, 397-405. [CrossRef]

19. Choi, H.; Hong, W.H. Analyzing the subsidy policy for the surroundings of nuclear power plants. Korean J. Public Financ. 2017, 10, 71-104. (In Korean)

20. Choi, Y.S.; Lee, B.W. Analysis of policy alternatives on the public acceptance of nuclear power plant in Korea. J. Nucl. Sci. Technol. 1995, 32, 218-225. [CrossRef]

21. Contu, D.; Strazzera, E.; Mourato, S. Modeling individual preferences for energy sources: The case of IV generation nuclear energy in Italy. Ecol. Econ. 2016, 127, 37-58. [CrossRef]

22. Choi, S. Exploring problems of the support program for the adjacent region of nuclear power plant site: Focused on Kori region. Korean J. Local Govern. Stud. 2009, 13, 223-244. (In Korean)

23. Chung, J. Awareness and development plan of communities for support of areas near nuclear power plants: Lesson from the US and Japan. Korean J. Asia Stud. 2013, 16, 125-156. (In Korean)

24. Sohn, J. A Study on the improvement of the public assistance programs for the neighboring area of nuclear power plant. Anam. Law Rev. 2014, 44, 283-315. (In Korean)

25. Haaijer, R.; Wedel, M. Conjoint choice experiments: General characteristics and alternative model specification. In Conjoint Measurement: Methods and Applications, 3rd ed.; Gustafsson, A., Herrmann, A., Huber, F., Eds.; Springer: Berlin/Heidelberg, Germany, 2003; pp. 371-412.

26. Raghavarao, D.; Wiley, J.B.; Chitturi, P. Choice-Based Conjoint Analysis: Models and Designs; CRC Press: Boca Raton, FL, USA, 2011.

27. Chung, W.; Yeung, I.M.H. Attitudes of Hong Kong residents toward the Daya Bay nuclear power plant. Energy Policy 2013, 62, 1172-1186. [CrossRef]

28. Daekyeong Daily, Uljin County Electricity Fee Support Expansion in 2018. Available online: http:/ / www. hidomin.com/news/articleView.html?idxno=347031 (accessed on 27 March 2018).

29. KEPCO Big Data Center. Average Household Power Consumption. Korea Electric Power Corporation. Available online: https://home.kepco.co.kr/kepco/BD/BDBAPP005/BDBAPP005.do? menuCd=FN33020105 (accessed on 15 October 2017). (In Korean)

30. Jami, A.A.; Walsh, P.R. Wind power deployment: The role of public participation in the decision-making process in Ontario, Canada. Sustainability 2016, 8, 713. [CrossRef]

31. Langer, K.; Decker, T.; Menrad, K. Public participation in wind energy projects located in Germany: Which form of participation is the key to acceptance? Renew. Energy 2017, 112, 63-73. [CrossRef]

32. Huppe, M.; Weber, J. Effects of distance, age and sex upon attitudes toward nuclear power plants: An empirical study. Zbl. Hyg. Umweltmed. 1999, 202, 331-344. [CrossRef]

33. Noh, S. Analysis of Nuclear Acceptance Using SNS Big Data and Policy Implications; Nuclear Policy Brief Report; Korea Atomic Energy Research Institute: Daejeon, Korea, 2015. (In Korean)

34. Frantál, B.; Malý, J.; Ouředníček, M.; Nemeškal, J. Distance matters. Assessing socioeconomic impacts of the Dukovany nuclear power plant in the Czech Republic: Local perceptions and statistical evidence. Morav. Geogr. Rep. 2016, 23, 54-63. [CrossRef]

35. Won, D. A study on the relationship between risk perception and geographical distance to nuclear power plant. Korean Assoc. Public Financ. 2016, 2, 1-23. (In Korean)

36. McFadden, D. Conditional Logit Analysis of qualitative choice behavior. In Frontiers of Econometrics; Zarembka, P., Ed.; Academic Press: New York, NY, USA, 1974; pp. 105-142. 
37. Train, K.E. Discrete Choice Methods with Simulation, 2nd ed.; Cambridge University Press: Cambridge, UK, 2009.

38. Allenby, G.M.; Rossi, P.E. Marketing models of consumer heterogeneity. J. Econom. 1998, 89, 57-78. [CrossRef]

39. Huber, J.; Train, K. On the similarity of classical and Bayesian estimates of individual mean partworths. Market Lett. 2001, 12, 259-269. [CrossRef]

40. Edwards, Y.D.; Allenby, G.M. Multivariate analysis of multiple response data. J. Mark. Res. 2003, 40, 321-334. [CrossRef]

41. Choi, Y.S.; Lee, S.H.; Cho, N.Z.; Lee, B.W. Development of the public attitude model toward nuclear power in Korea. Ann. Nucl. Energy 1998, 25, 923-936. [CrossRef]

42. Roh, S.; Lee, J.W. Differentiated influences of risk perceptions on nuclear power acceptance according to acceptance targets: Evidence from Korea. Nucl. Eng. Technol. 2017, 49, 1090-1094. [CrossRef]

43. Kukmin Ilbo, Nuclear Power Plant Serious, 59.8\% Said "Not in Front of My House". Available online: http:/ / news.kmib.co.kr/article/view.asp?arcid=0922904086\&code=11151400\&cp=nv (accessed on 22 March 2018). (In Korean)

44. Vittes, M.E.; Pollock, P.H.; Lilie, S.A. Factors contributing to NIMBY attitudes. Waste Manag. 1993, 13, 125-129. [CrossRef]

45. Greenberg, M.R. NIMBY, CLAMP, and the location of new nuclear-related facilities: U.S. national and 11 site-specific surveys. Risk Anal. 2009, 29, 1242-1254. [CrossRef] [PubMed]

46. Jenkins-Smith, H.C.; Silve, C.L.; Nowlin, M.C.; deLozier, G. Reversing nuclear opposition: Evolving public acceptance of a permanent nuclear waste disposal facility. Risk Anal. 2011, 31, 629-644. [CrossRef] [PubMed]

47. Gallardo, A.H.; Matsuzaki, T.; Aoki, H. Geological storage of nuclear wastes: Insights following the Fukushima crisis. Energy Policy 2014, 73, 391-400. [CrossRef]

48. Sun, C.; Lyu, N.; Ouyang, X. Chinese public willingness to pay to avoid having nuclear power plants in the neighborhood. Sustainability 2014, 6, 7197-7223. [CrossRef]

49. Kaenzig, J.; Heinzle, S.L.; Wustenhagen, R. Whatever the customer wants, the customer gets? Exploring the gap between consumer preferences and default electricity products in Germany. Energy Policy 2013, 53, 311-322. [CrossRef]

50. Huh, S.Y.; Woo, J.; Lim, S.; Lee, Y.G.; Kim, C.S. What do customers want from improved residential electricity services? Evidence from a choice experiment. Energy Policy 2015, 85, 410-420. [CrossRef]

51. Huh, S.Y.; Lee, C.Y. A demand-side perspective on developing a future electricity generation mix: Identifying heterogeneity in social preferences. Energies 2017, 10, 1127. [CrossRef]

52. Adalja, A.A.; Sell, T.K.; Ravi, S.J.; Minton, K.; Morhard, R. Emergency preparedness in the 10-mile emergency planning zone surrounding nuclear power plants. J. Homel. Secur. Emerg. 2014, 12, 81-100. [CrossRef]

53. US NRC, Emergency Planning Zones. 2014. Available online: https://www.nrc.gov/about-nrc/emergpreparedness/about-emerg-preparedness/planning-zones.html (accessed on 9 January 2019).

54. Lee, C.Y. Cross Country Study on Levelized Cost of Solar PVs; Korea Energy Economics Institute Press: Ulsan, Korea, 2017.

55. Zoellner, J.; Schweizer-Ries, P.; Wemheuer, C. Public acceptance of renewable energies: Results from case studies in Germany. Energy Policy 2008, 36, 4136-4141. [CrossRef]

56. Schweizer, P.J.; Renn, O.; Kock, W.; Bovet, J.; Benighaus, C.; Scheel, O.; Schroter, R. Public participation for infrastructure planning in the context of the German "Energiewende". Util. Policy 2016, 43, $206-209$. [CrossRef]

57. Orme, B. Formulating Attributes and Levels in Conjoint Analysis; Sawtooth Software: Washington, DC, USA, 2002.

(C) 2019 by the authors. Licensee MDPI, Basel, Switzerland. This article is an open access article distributed under the terms and conditions of the Creative Commons Attribution (CC BY) license (http:/ / creativecommons.org/licenses/by/4.0/). 